\title{
Suicidal thoughts among university students: The role of mattering, state self-esteem and depression level
}

\author{
Kususanto D. Prihadi, Charon Y.S Wong, Erina Y.V. Chong, Kate Y.X. Chong \\ Department of Psychology, HELP University, Malaysia
}

\begin{tabular}{l} 
Article Info \\
\hline Article history: \\
Received Mar 14, 2020 \\
Revised Jun 16, 2020 \\
Accepted Jul 23, 2020
\end{tabular}

\section{Keywords:}

Depression level

Mattering

State self-esteem

Suicide ideation

\begin{abstract}
The protective role of mattering on suicide ideation among university students was examined. Our study is grounded in the InterpersonalPsychological Theory of Suicide, which led to a hypothesis that between depression levels and state self-esteem has significant serial multiple mediating effects on the relationship between mattering and suicide ideation. University students from various nationality who study in Indonesia and Malaysia ( $\mathrm{n}=509)$ responded to General Mattering Scale, State Self-Esteem Scale, Beck's Depression Inventory, and Suicide Ideation Attributes Scale, as well as demographic details including their gender, spirituality, education, birth order and nationality. The result of Bootstrap analyses with 95\% confident interval from 5000 samples suggested that the serial mediation partially occurred to the link between mattering and suicide ideation.
\end{abstract}

This is an open access article under the $\underline{C C B Y-S A}$ license.

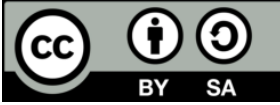

\section{Corresponding Author:}

Kususanto Ditto Prihadi,

Department of Psychology,

Higher Education Learning Philosophy (HELP) University,

No.2 Persiaran Cakerawala, Section U4, 40150, Shah Alam, Selangor, Malaysia.

Email: prihadi.k@help.edu.my

\section{INTRODUCTION}

The increase of suicide cases among young adults has reached an alarming level in 2018 when the World Health Organization announced that suicide is the second leading cause of death of individuals aged between 15 to 29, and projected to have 25\% increase by 2030 [1]. Moreover, the recent suicide cases also prevalent among general population, instead of only among psychiatric patients or individuals diagnosed with mental illness [2]. In line with that, the prevalence of suicide ideation among 50,054 university students was discovered to be $21 \%$ and $4.2 \%$ of them had reported suicide attempts [3]. Previous studies among general population reported various risk factors of suicidal thoughts, such as $[4,5]$, exposure to suicide among relatives or friends [6], abused childhood [7], sexual orientation [8], social anxiety [9] and depression [10]. Among the aforementioned studies, depression was considered as one of the most commonly known predictors of suicide ideation as past and recent studies have found a strong correlation between the variables [11-13]. Depression was also suggested to be the most leading mental disorder correlated with suicidality [14].

Depression has been reported as a strong and prevalent predictor of suicide ideation; in 2006, Ang and Huan reported that depression explained $74 \%$ variance of suicide ideation among students who experienced academic stress, and one-point increment of depression predicted 0.6 increase of suicide ideation [15]. This study was in line with newer studies on how depression contributed to suicide ideation [16-18]. Additionally, Li, Dorstyn, and Jarmon conducted a systematic review on many previous studies and reported that 14 out of 29 studies involving pooled participants of 11,557 university students demonstrated a significant and strong relationship between depression and suicide ideation [19]. 
Nevertheless, depression was reported to be stemmed from different factors. On a quite recent study among Asians who studies in the United States (US), Cornejo and colleagues suggested that depression among their population was caused by the gap between their family culture and the fact that they are more acculturated towards the US [20]. Nevertheless, depression also takes place among students who study in places without significant cultural differences, Kwak and Ickovics stated that depression among Korean students who study in Korean universities is rooted from academic stress [18]. In the context of Malaysia - one of the locations where our data was collected - being young members of certain ethnic group is considered as a factor of depression that might lead to suicide ideation [16], together with lack of spirituality and perceived social support [21]. Different from Korean samples, Malaysian samples showed that their depression levels are related to tobacco use, unwanted or abusive sexual experiences, exploitation or violenc [12], as well as low self-esteem and loneliness [22]. Thus, because depression can be caused by many factors, it is worthwhile to discuss the theoretical perspective on how suicide ideation is being started by depression.

One of the few major theories in suicide ideation is the Interpersonal-Psychological Theory of Suicide (IPTS), which explained that suicide ideation is a result of perceived burdensomeness ("my death is more meaningful to others than my life") and thwarted belongingness ("I am lonely") [23]. Depression among university students in Malaysia led them to feel that they are burdensome to others, and lack of social supports thwarted their sense of belongingness, therefore they develop suicide ideation. Howe ver, one might not perceive themselves to be burdensome when they perceive and believe that their presence is meaningful [24], and their sense of belongingness can also be protected if they believe they belong to their social environment to certain extent [25]. These two factors, sense of social belonging and sense of social meaning are parts of another construct called mattering $[24,25]$. In other words, IPTS explained that when one feels matter enough to have no perceived burdensomeness and thwarted belongingness, they would not likely to develop suicide ideation.

Referred to one's sense that one matters to others [26], mattering can be taken as a protective factors of suicide ideation [27]. The robustness of mattering as a protective factor of suicide ideation was also reported in a more recent study in Australian setting, where people with a lower sense of mattering had a higher likelihood of suicide ideation even after controlling for gender and relationship status [28]. Accordingly, the findings of Vanderhost et al suggested that one-point increment of mattering might reduce the chance of suicide ideation by 0.43 points, and it can explain $18 \%$ variance of suicide ideation reduction [29]. Supporting that, a recent meta-analysis study by Flett, Khan and Su showd that the feelings of 'not mattering' is a potential indicator of suicide ideation [30]. While it is evident that mattering is a robust protective factor of suicide ideation, it is interesting that mattering is also considered a protective factor for depression. A study among adolescents in China indicated that the higher level of mattering is associated to lower level of depression, whereby an increase of mattering predicted .36 point of decrease among $36 \%$ of variance of depression [31]. The protective feature of mattering on depression can also be seen in different contexts; in the context of interpersonal relationship, mattering mediated the relationship between interpersonal conflict and depressive symptoms, as well as partially mediated the contribution of communication awkwardness and partner influence dynamics on depressive symptoms [32]. Hypothetically, the role of mattering in decreasing suicide ideation can be explained through the way it protects individuals from depression.

Nevertheless, mattering was not the only reported protective factors for depression and suicide ideation. Studies among various population have also captured the significant contribution of low state of self-esteem on suicide ideation [11,33-35], which means that individuals in a higher self-esteem state are not likely to develop suicidal thoughts. One example is the work of Wilburn and Smith in 2005, which reported that one-point improvement of self-esteem can explain $11 \%$ variance of 35 points reduction of suicidal thoughts development, while the effect was quite strong, the prevalence was not that high [35]. Few years later, Aradilla-Herrero reported that one-point increment in self-esteem can account for almost $40 \%$ of the decrease of suicide ideation [11]. Related to depression, self-esteem was reported to be the protective factor of depression among 4995 adolescents (1002 American and 3993 Koreans), high self-esteem level protected them from having depressed mood caused by body dissatisfaction [36]. While it can be hypothetically concluded that people will not develop suicide ideation while they are in a higher state of self-esteem, the association between self-esteem state and depression should be reviewed, due to the establishment that depression is the more prominent cause of suicidal thoughts.

To explain the link between the state of self-esteem and depression level, a study in the context of cyberbullying indicated that self-esteem is one of the serial mediators of the contribution of cyber-victimized perception on depression where the negative total effect of state self-esteem on depression was considered moderately strong with -0.33 coefficient and prevalent by explaining $55 \%$ of the variance of the decrease in depression [37]. In line with that, a meta analysis of longitudinal studies yielded a result that individuals in the lower state of self-esteem tend to seek negative feedbacks from others to verify their negative 
self-concept, which develop the sense of depressed [38]. Both of the aforementioned studies indicated that higher state of self-esteem predicts lower level of depression, hence it was hypothesized that the significance of depression will diminish the significance of state self-esteem in predicting suicide ideation.

While self-esteem seems to hold the similar protective role to mattering in terms of decreasing suicide ideation through a decrease in depression, the relationship between the two factors have also been studied for quite a while. In 2004, Elliott, Kao and Grant, advocated that mattering and self-esteem are significantly correlated [39]. More recent studies reported directional relationship between the two variables, with mattering as the predictor. In 2017, a study in educational setting by Dueñas and Gloria [40] reported that students' sense self-esteem was significantly related to whether they felt they mattered to others. Similarly, a year before, Flet, Goldstein, Pechenkov, Nepon and Wekerle suggested that people who feel like they do not matter to others are likely to have the kind of negative evaluation on their own personal identity [41]. Furthermore, the recent work by Matera, Bosco and Meringolo [42] supported the aforementioned studies by reporting that the increment of sense of mattering to friends among adolescence might increase one's sense of belongingness, whereas the perception of mattering to family contributed to enhancing one's sense of meaning in life. The aforementioned studies in this paragraph suggested that the sense of mattering protected individuals from having lower state self-esteem, which leads to another hypothesis that self-esteem will mediate the contribution of mattering to depression.

While mattering was reported to predict suicide ideation, depression level was reported to be a stronger predictor that can explain way more variance of suicide ideation than mattering. On the other hand, self-esteem was considered as a more prevalent predictor of depression level. Thus, this present study is significant in order to show the interrelationship among the involved variables. Therefore, it was hypothesized that low sense of mattering will lead individuals to a lower state of self-esteem, and it will certainly increase their depression level. Furthermore, high level of depression might lead them to develop suicidal thoughts. In other words, the past studies we discussed led us to a hypothesis that state self-esteem and depression level will engage in a serial mediation role to the protective feature of mattering on suicide ideation. The hypothetical model is illustrated in Figure 1.

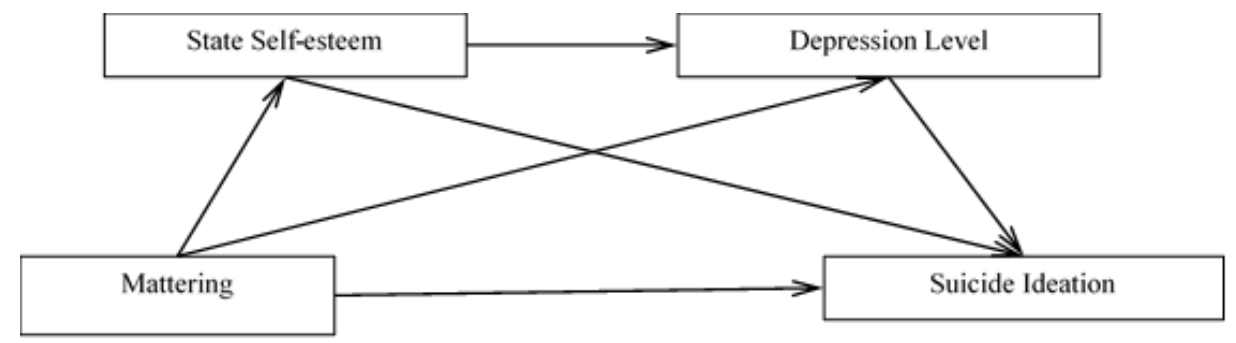

Figure 1. Hypothetical model of the serial mediation of state self-esteem and depression level on the relationship between mattering and suicide ideation

\section{RESEARCH METHOD}

\subsection{Design}

As the present study aimed to determine if there was a serial mediation effect of state self-esteem and depression level on the relationship between mattering and suicide ideation, the research design of the present study was a non-experimental correlational research design. Four variables examined were mattering, state self-esteem, depression level and suicide ideation.

\subsection{Participants}

A total of 508 participants were purposively recruited from students who are registered in any university in Malaysia and Indonesia, with Malaysian nationality $(n=289)$, Indonesian nationality $(n=200)$ and other nationalities $(\mathrm{n}=19)$. On purposely, only participants who are registered to higher education institutions in Malaysia and Indonesia were recruited. Their age is ranged from 17 to 36 years of age $(\mathrm{M}=20.21, \mathrm{SD}=1.95)$. Of the total sample, 152 were males $(29.92 \%), 347$ were females $(68.31 \%)$ and 9 preferred not to say $(1.77 \%)$. Whereas regarding their religiosity and spirituality, 202 participants stated that they are religious or spiritual, 199 participants stated they are neither religious nor spiritual, and 107 of them stated that they are not sure about their spirituality. 


\subsection{Materials}

Mattering was measured by General Mattering Scale [43]. It is a 24-item self-reported instrument, consisting of items related to elements of mattering, for example, awareness, importance and reliance. The questionnaire was rated on a 5-point Likert scale, ranging from 1 (strongly disagree) to 5 (strongly agree); for example, "When people need help, they come to me" and "People generally know when I am around". A score of 5 was assigned to the response indicating the greatest degree of mattering whereas a score of 1 was assigned to the response indicating the least degree of mattering. The scores of each item were summed up to obtain a total score for level of mattering, after reverse-scoring. Higher total score on General Mattering Scale indicated that the participant had higher level of mattering. It was reported that content validity, construct validy, discriminant validity, and reliability of General Mattering Scale were satisfactory with Cronbach's alpha coefficient of $.90, .92$ and .89 from a total of three samples.

State self-esteem was measured by State Self-Esteem Scale (SSES) [44]. SSES was a 20-item selfreported measure which was developed to measure the extent of participants' state self-esteem at that moment when they were answering the scale. The scale was rated on 5-point Likert scale, ranging from 1 (not at all) to 5 (extremely); for example, "I feel satisfied with the way my body looks right now". The scores of each item were summed up to obtain a total score for state self-esteem, after reverse-scoring. Higher total score on SSES indicated that the participant had higher level of state self-esteem at the moment when they answered the questionnaire. It was reported that the construct validity, concurrent validity, discriminant validity and reliability of SSES were satisfactory with Cronbach's alpha coefficient of .92.

The Beck's Depression Inventory (BDI) [45] was used to measure depression level. BDI was a 21-item self-scored inventory which consists of 21 clinically derived symptom-attitude related to the characteristics and symptoms of depression according to systematic observation and documentations of depressed patients done by the senior author. The symptom-attitude were categorized into 21 categories where each category expresses a specific behavioural pattern of depression such as pessimism, sense of failure, guilty feeling, irritability, self punitive wishes et cetera. The 21 categories consisted of a graded series of 4 self-evaluative statements with allocation of numerical values from 0-3 which were classified to indicate the level of the symptom-attitude of depression from neutral to maximal intensity. For example, in one of the symptom-attitude categories, "0" was allocated to "My appetite is no worse than usual" where as " 3 " was allocated to "I have no appetite at all anymore". The scores of each category were summed up to obtain a total score for depression level. Higher total score on BDI indicated that the participant had higher level of depression. It was reported that the validity of BDI was satisfactory; whereas internal consistency and stability showed a high degree of reliability.

Suicide ideation was measured by the Suicidal Ideation Attributes Scales (SIDAS) [46]. SIDAS was a scale containing five questions related to the rate of occurrence and intensity of suicidal thoughts with 11-point Likert scale; for instance, "In the past month, to what extent have you felt tormented by thoughts about suicide?". The scores of each item were summed up to obtain a total score for degree of suicide ideation, after reverse-scoring. Higher total score on SIDAS indicated that the participant had higher degree of suicide ideation. The convergent validity and internal consistency of SIDAS were reported to be satisfactory with Cronbach's alpha coefficient of .89 .

\subsection{Procedures}

Participants were purposively recruited based on the requirement of the present study, which was to be students who are registered in any university in Malaysia and Indonesia. Link to the Google Form Survey is posted on social media pages of the researchers, including Instagram, Facebook, and WhatsApp story or groups. Willing participants followed a link to a Google Form Survey where they stated their approval to the informed consent form. Afterwards they were provided with a demographic questionnaire; where age, gender, nationality, ethnicity, birth order, spirituality and level of their current studies were asked. The question on spirituality that was asked in the demographic questionnaire was necessary due to the fact that suicide can be considered as religious issue in Malaysian and Indonesian culture. Next, the four scales included were General Mattering Scale, SSES, BDI and SIDAS. In order to improve the comprehensiveness among participants from Indonesia, bilingual version of the scales was utilized. A panel of experts in languages and social psychology was involved in the back-translation process from English to Indonesian. In addition, the Google Form was set to disallow participants to move to the next survey when they have not responded to all the items in the previous survey. This method is chosen to eliminate the possibilities of missing items. Their confentiality was also warranted by not asking them to leave their email or any identity within the form. Random participants reported that they required around 30 minutes to complete the entire English version of the scales, and 40 minutes to complete the entire bilingual version of the scales. 


\section{RESULTS AND DISCUSSION}

The aim of the study was to examine if the state self-esteem and depression level were involved in a serial mediation effect in the relationship of mattering and suicide ideation among students in who are registered in any university in Malaysia and Indonesia. Each participant's score on the four scales were calculated as explained in the "Materials" section. The analyses were conducted using PROCESS Macro Model 6 version 3 [47] of SPSS 20, in order to conduct the bootstrap method to test the serial mediation. Bootstrap method with 5000 sample and $95 \%$ confident interval was utilized in the data analyses because it is one of the most robust method conduct path analyses in any normality and collinearity condition [47]. The frequency and distribution of data obtained from all the participants $(n=508)$ were depicted in Table 1 .

Table 1. Distribution of data

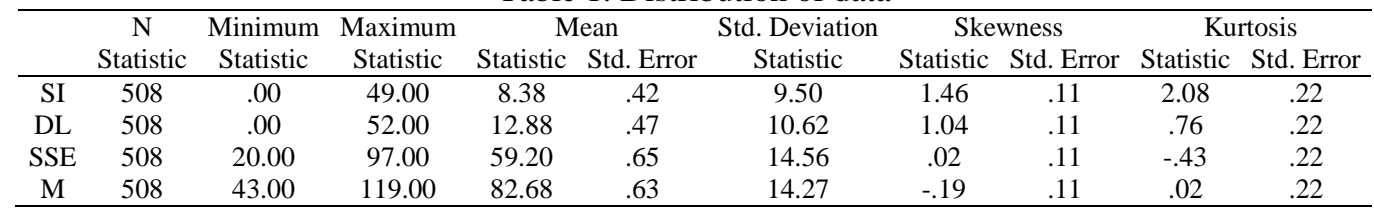

As can be seen in Table 1, the data of suicide ideation and depression level was skewed to the left, which indicated that suicide ideation and depression level were averagely low among the overall participants. On the other hand, mattering and state self-esteem are normally distributed among the overall participants. It can be concluded that in general, the participants do not have high level of depression, and do not develop high ideation of ending their life. Table 2 illustrates the Multiple regression among mattering (M), state selfesteem (SSE), depression level (DL) and suicide ideation (SI).

Table 2. Multiple regression among the variables $(\mathrm{n}=508)$

\begin{tabular}{lccccccc}
\hline & $\mathrm{R}^{2}$ & $\mathrm{~F}$ & $\mathrm{t}$ & $\mathrm{df1}$ & $\mathrm{df} 2$ & $\beta$ & $\mathrm{p}$ \\
\hline $\mathrm{M} \rightarrow \mathrm{SSE}$ & .403 & 341.555 & 18.841 & 1.000 & 506.000 & .648 & .000 \\
$\mathrm{M} \rightarrow \mathrm{DL}$ controlling for SSE & .537 & 293.182 & -3.613 & 2.000 & 505.000 & -.105 & .000 \\
$\mathrm{M} \rightarrow$ SI controlling for SSE and DL & .398 & 111.076 & -2.253 & 3.000 & 504.000 & -.068 & .025 \\
\hline
\end{tabular}

Mattering as a model significantly predicted level of state self-esteem, $\mathrm{F}(1,506)=341.56, \mathrm{p}<.001$, $\mathrm{R} 2=.40$, explaining $40.3 \%$ of the variance in level of state self-esteem. Mattering significantly predicted level of state self-esteem, $\mathrm{b}=.65, \mathrm{t}(506)=18.48, \mathrm{p}<.001$.

Overall model of mattering and state self-esteem significantly predicted depression level, F $(2,505)$ $=293.18, \mathrm{p}<.001, \mathrm{R}^{2}=.54$, explaining $53.7 \%$ of the variance in level of depression. Mattering significantly predicted depression level when controlling for state self-esteem, $b=-.11, \mathrm{t}(505)=-3.61, \mathrm{p}<.001$.

Overall model of mattering, state self-esteem and depression level significantly predicted suicide ideation, $\mathrm{F}(3,504)=111.08, \mathrm{p}<.001, \mathrm{R}^{2}=.40$, explaining $39.8 \%$ of the variance in suicide ideation. Mattering significantly predicted suicide ideation when controlling for state self-esteem and depression level, $\mathrm{b}=-.07, \mathrm{t}(504)=-2.25, \mathrm{p}=.025$.

Next analyses were conducted in order to test the total and direct effect of mattering on suicide ideation, as well as the indirect effect through state self-esteem and depression level, followed by the serial indirect effect through self-esteem and depression level. Table 3 summarizes the results of the bootstrap analyses.

Table 3. Total, direct and indirect effect of mattering on suicide ideation

\begin{tabular}{|c|c|c|c|c|c|c|c|}
\hline \multirow{2}{*}{ Effect } & & \multirow{2}{*}{$\mathrm{R}^{2}$} & \multirow{2}{*}{$\mathrm{p}$} & \multirow{2}{*}{$\beta$} & \multirow{2}{*}{ BootSE } & \multicolumn{2}{|c|}{$95 \% \mathrm{CI}$} \\
\hline & & & & & & Lower & Upper \\
\hline Total & $\mathrm{M}$ as a model $\rightarrow$ SI & .140 & .000 & -.249 & & -.303 & -.196 \\
\hline Direct & $\mathrm{M} \rightarrow \mathrm{SI}$ & & .025 & -.068 & & -.127 & -.009 \\
\hline Total ind & Total M + Indirect effect $1 \& 2$ & & & -.182 & .028 & -.238 & -.128 \\
\hline Ind1 & $\mathrm{M} \rightarrow \mathrm{SSE} \rightarrow \mathrm{SI}$ & & & .063 & .031 & .002 & .121 \\
\hline Ind2 & $\mathrm{M} \rightarrow \mathrm{DL} \rightarrow \mathrm{SI}$ & & & -.064 & .021 & -.107 & -.027 \\
\hline Serial Med & $\mathrm{M} \rightarrow \mathrm{SSE} \rightarrow \mathrm{DL} \rightarrow \mathrm{SI}$ & & & -1.81 & .023 & -.227 & -135 \\
\hline
\end{tabular}


The indirect effect of mattering on suicide ideation through state self-esteem was significant $(b=$ $.06)$, as the bias-corrected bootstrapped confidence interval did not contain zero, $\mathrm{BCa} \mathrm{Cl}[.003, .121]$. The indirect effect of mattering on suicide ideation through depression level was significant $(b=-.06)$, as the bias-corrected bootstrapped confidence interval did not contain zero, $\mathrm{BCa} \mathrm{Cl}$ [-.107, -.027]. The indirect effect of mattering on suicide ideation through state self-esteem and depression level was significant $(\mathrm{b}=$ .18 ), as the bias-corrected bootstrapped confidence interval did not contain zero, $\mathrm{BCa} \mathrm{Cl}[-.227,-.135]$. All the mediations were significant, due to the fact that both upper and lower confident interval among 5000 samples are similarly negative or similarly positive among all the effects. Serial mediation of state self-esteem and depression level occurred on the relationship between mattering and suicide ideation. However, all the mediation effects are considered as partial mediation because direct effect of mattering was still significant $(\mathrm{p}=.025)$ despite controlling for all the mediator variables.

The present study was designed to provide an understanding and explanation of relationship between mattering and suicide ideation using state self-esteem and depression level as serial mediators. There were six hyphotheses proposed in this study. Firstly, mattering as a model will significantly predict state selfesteem. Secondly, mattering will not predict depression level when controlling for state self-esteem. Third, mattering will not predict suicide ideation when controlling for state self-esteem and depression level. Fourth, state self-esteem will fully mediate the link between mattering and suicide ideation. Fifth, depression level will fully mediate the link between mattering and suicide ideation. Lastly, state self-esteem and depression level will perform full serial multiple mediation on the link between mattering and suicide ideation.

The hypotheses might sound similar to the work of Elliot, Colangelo and Gelles [48], which reported that self-esteem and depression were significant mediators of the relationship between mattering and suicide ideation. The similarity between their study and the present study is that the present study has also collected the data of age, gender, and spirituality or religiosity, as these three factors had been reported to be significantly related to suicide ideation and mattering in their study. However, there is a population and methodological gaps between the present study and the work of Elliot and his colleagues in 2005; they have conducted semi-structured interview to collect data from participants between 11 and 18 years of age, while in the present study, a survey method was employed in order to collect data from university and college students ranging from diploma to doctoral degree. This methodological difference leads to another three major differences; first, the present study focused on depression level and state self-esteem, instead of depression and self-esteem. In their study, the level of depression was measured by a single-item questionnaire and the results were categorized into "no" and "yes"; whereas in the present study, the use of Beck's Depression Inventory allowed us to investigate the level of depression reported by the participants in terms of "high level" or "low level". In other words, instead of being diagnosed with no depression, participants who scored low levels of depression in the scale showed that they have a low level of depression. The second methodological difference is that the present study measured state self-esteem instead of selfesteem. State self-esteem refers to the state components of self-esteem [49], which fluctuates according to the social environment feedback of self-evaluation, unlike the general self-esteem, which is more stable along the lifetime [50]. State self-esteem, instead of general self-esteem, is employed because in the age of young adults, general self-esteem tends to be stable over time, hence its link to mattering, perceived depression, or suicide ideation might not be visible through survey questions. The third difference in terms of methods is that the present was done to test the hypothesis of serial mediation of perceived depression and state self-esteem, while the work of Elliot et al tested the hypothesis that self-esteem and depression did not predict each other.

The results depicted in Table 2 showed that mattering are a significant predictor of state self-esteem. Thus, the first hypothesis was supported. However, the second and third hypotheses were not supported as mattering was still a significant predictor of depression level when controlling for state self-esteem and was still a significant predictor of suicide ideation when controlling fr state self-esteem and depression level. This indicated that the mediator variables have only partially mediated the link between mattering and suicide ideation. Table 3 shows that the last three hypotheses were rejected by the analyses of indirect effect 1,2 , and 3 , because the mediation effects were only partial despite significant. The relationship between mattering and suicide ideation was mediated by both state self-esteem and depression level. This finding suggested that mattering is a robust negative predictor of suicide ideation among individuals who are studying in Malaysian and Indonesian universities, where the serial mediation of state self-esteem and depression level can only partially explain its negative contribution. In other words, the higher the mattering, individual's tendency to develop suicidal thought is lower, as the state self-esteem increases and depression level decreases. The aforementioned findings can be explained by Interpersonal-Psychological Theory of Suicide (IPTS) [23]; the elements of importance and reliance of mattering protect the young adults from perceiving themselves to be burdensome, and the element of awareness keeps them from perceiveing that they do not belong. Therefore, in line with the work of Drabenstott [25] and Quaye and Chang [24], young 
adults with higher level of mattering would not develop sustained hopelessness that led them to depression and suicide ideation.

\subsection{Scope and limitations}

There were several limitations in the present study to be noted of. Firstly, the present study utilized self-reported scales in determining participants' level of mattering, state self-esteem, depression level and severity of suicide ideation. Although the inventories used in the present study were reliable and validated, the nature of self-reported scale contributed to the possibility of participant bias or response bias as participants tend to give response based on their perception of the desired response by researchers. This could be improved by employing informant reports such as scales responded by close family member or friend of the study subjects, or clinical interviews conducted by trained psychologists. Secondly, the nature of the present study as a non-experimental correlational design limited the researchers from making causal assertions. Longitudinal analysis could be employed to enhance the present study as it provides for the possibility of causal model between mattering and suicide ideation by showing the direction of the effects.

\subsection{Implications and suggestions}

Findings of the present study contributed to the literature by explaining the relationship between mattering and suicide ideation via a serial mediator, state self-esteem and depression level. The significant mediating effect of the serial mediator indicated that it was the higher state self-esteem and lower depression level experienced by individuals with more mattering that explains their likelihood to have lower severity of suicide ideation. Although state self-esteem and depression level were found to partially mediate the link between mattering and suicide ideation, the significance of state self-esteem and depression level in predicting suicide ideation when controlling of other variables suggested the necessity for future research to investigate an effective way to protect university students from suicide ideation, by taking any factor that decreases their state self-esteem or increases their depression level into account.

The findings can also contribute to the field of suicide prevention by having both state self-esteem and depression level of individuals assessed as a preventive measure of suicide, such as coming out with intervention program that can boost state self-esteem and decrease likelihood of depression among individuals via improving sense of mattering. For example, by knowing that mattering consisted of three elements namely awareness, importance and reliance [26], the delivery of education should make sure that the presence of the students are acknowledged, and that they are considered important individuals for the educators, the institutions and their peers. It is also important to ensure that students can sense that they are considered as reliable members of the society. Another suggestion is to add other variables, such as anxiety, learned helplessness and perceived social support into the model advocated in the present study. The reason of including the three variables is because mattering was reported to be a robust predictor, yet it could only account for $14 \%$ variance of suicide ideation among overall participants. Furthermore, as participants in the present study generally reported low levels of suicide ideation and depression level, it is also suggested for future research to include at-risk participants, such as those who have already been diagnosed with depression or had attempted suicide prior to the data collection. It is expected that future research following the suggestions will yield deeper knowledge in reducing suicidal tendency among young adults.

\section{CONCLUSION}

Findings of the present study highlighted that while mattering is a robust negative predictor of suicide ideation, state self-esteem and depression involved in partial serial mediation in explaining the link between mattering and suicide ideation. At a glance, individuals with higher level of mattering were reported to have lower severity of suicide ideation as they experience higher level of state self-esteem and lower level of depression. It can be summarized that while improving mattering via improving state self-esteem and reducing depression level might work to reduce the tendency of suicide ideation among ideation among university students, it is necessary for future research to explore other potential and possible variables as an explanation mechanism of the relationship between mattering and suicide ideation, as the findings also showed that it was a partial serial mediation model. Future research could also extend the study to clinical samples and examine the causality direction in this relationship by conducting a longitudinal study.

\section{ACKNOWLEDGEMENTS}

This study is fully funded by the Research Management Center of HELP University, Malaysia, through Internal Research Grant Scheme (IRGS). This study is a part of a research by the Research Center of Mattering, Cyberpsychology and Games, Department of Psychology, HELP University. 


\section{REFERENCES}

[1] W. H. O. WHO, "World Health Organization," 2019. [Online]. Available: https://www.who.int/news-room/factsheets/detail/suicide

[2] S. M. Bae, Y. J. Lee, I. H. Cho, S. J. Kim, J. S. Im, and S. J. Cho, "Risk factors for suicidal ideation of the general population," Journal of Korean medical science, vol. 28, no. 4, pp. 602-607, 2013.

[3] B. Sivertsen, et al., "Suicide attempts and non-suicidal self-harm among university students: prevalence study," BJPsych open, vol. 5, no. 2, pp. 1-8, 2019.

[4] X. L. Cao, et al., "Prevalence of suicidal ideation and suicide attempts in the general population of China: a meta-analysis," The International Journal of Psychiatry in Medicine, vol. 49, no. 4, pp. 296-308, 2015.

[5] J. D. Ribeiro, et al., "Capability for suicide interacts with states of heightened arousal to predict death by suicide beyond the effects of depression and hopelessness," Journal of affective disorders, vol. 188, pp. 53-59, Dec 2015.

[6] M. Maple, et al., "Is Exposure to Suicide Beyond Kin Associated with Risk for Suicidal Behavior? A Systematic Review of the Evidence," Suicide and Life-Threatening Behavior, vol. 47, no. 4, pp. 461-474, 2016.

[7] M. S. Martin, et al., "Child abuse and the prevalence of suicide attempts among those reporting suicide ideation," Social psychiatry and psychiatric epidemiology, vol. 51, no. 11, pp. 1477-1484, 2016.

[8] T. Salway, L. E. Ross, C. P. Fehr, J. Burley, S. Asadi and a. L. A. T. Blake Hawkins, "A systematic review and meta-analysis of disparities in the prevalence of suicide ideation and attempt among bisexual populations," Archives of sexual behavior, vol. 48, no. 1, pp. 89-111, 2019.

[9] E. A. Crawford, et al., "Somatic Symptoms of Anxiety and Suicide Ideation Among Treatment-Seeking Youth With Anxiety Disorders," Suicide and Life-Threatening Behavior, vol. 49, no. 3, pp. 811-825, 2019.

[10] K. Minkoff, E. Bergman, A. T. Beck and R. Beck, "Hopelessness, depression, and attempted suicide," American Journal of Psychiatry, vol. 130, no. 4, pp. 455-459, 1973.

[11] A. Aradilla-Herrero, J. Tomás-Sábado and J. Gómez-Benito, "Associations between emotional intelligence, depression and suicide risk in nursing students," Nurse Education Today, vol. 34, no. 4, pp. 520-525, 2014.

[12] S. Mackenzie, et al., "Depression and suicide ideation among students accessing campus health care," American journal of orthopsychiatry, vol. 81, no. 1, pp. 101-107, 2011.

[13] R. D. Wetzel, "Hopelessness, depression, and suicide intent.," Archives of general psychiatry, vol. 33, no. 9, pp. 1069-1073, 1976.

[14] K. Hawton, C. Comabella, C. Haw and K. Saunders, "Risk factors for suicide in individuals with depression: a systematic review," Journal of affective disorders, vol. 147, no. 1-3, pp. 17-28, 2013.

[15] R. P. Ang and V. S. Huan, "Relationship between Academic Stress and Suicidal Ideation: Testing for Depression as a Mediator Using Multiple Regression," Child Psychiatry and Human Development, vol. 37, no. 2, pp. 133-143, 2006.

[16] F. A. Abdul Aziz, et al., "Factors Associated With Suicidal Attempt Among School-Going Adolescents in Malaysia," Asia Pacific Journal of Public Health, 2019.

[17] R. M. Hill, et al., "Depressive symptoms and perceived burdensomeness mediate the association between anxiety and suicidal ideation in adolescents," Archives of suicide research, vol. 22, no. 4, pp. 555-568, 2018.

[18] C. W. Kwak and J. R. Ickovics, "Adolescent suicide in South Korea: Risk factors and proposed multi-dimensional solution," Asian Journal of Psychiatry, vol. 43, pp. 150-153, 2019.

[19] W. Li, D. S. Dorstyn, and E. Jarmon, "Identifying suicide risk among college students: A systematic review," Death studies, vol. 43, no. 10, pp. 1-9, 2019.

[20] M. Cornejo, S. Agrawal, J. Chen, A. Yeung and N. H. Trinh, "Cultural Risk and Protective Factors for Depressive Symptoms in Asian American College Students," Adolescent Research Review, pp. 1-13, 2019.

[21] N. Ibrahim, et al., "The role of social support and spiritual wellbeing in predicting suicidal ideation among marginalized adolescents in Malaysia," BMC public health, vol. 19, no. 4, pp. 553-561, 2019.

[22] I. Uba, et al., "Does Self-Esteem Mediate the Relationship between Loneliness and Depression among Malaysian Teenagers?" Pertanika Journal of Social Science and Humanities, vol. 20, no. 1, pp. 179-188, 2012.

[23] T. E. Joiner, et al., "An interpersonal addendum to the hopelessness theory of depression: Hopelessness as a stress and depression generator," Journal of Social and Clinical Psychology, vol. 24, no. 5, pp. 649-664, 2005.

[24] S. J. Quaye and S. H. Chang, "Fostering cultures of inclusion in the classroom: From marginality to mattering," in Creating Campus Cultures, Routledge, pp. 98-115, 2012.

[25] M. Drabenstott, "A Matter of Life and Death: Integrating Mattering into the Interpersonal-Psychological Theory of Suicide," Suicide and Life-Threatening Behavior, vol. 49, no. 4, pp. 1006-1018, 2019.

[26] G. Flett, The psychology of mattering: Understanding the human need to be significant, Academic Press, 2018.

[27] J. Whitlock, et al., "Connectedness and suicide prevention in college settings: Directions and implications for practice," Ithaca, NY: Brofenbrenner Center for Translational Research, Cornell University, pp. 1-34, 2012.

[28] A. Milner, K. M. Page and A. D. LaMontagne, "Perception of mattering and suicide ideation in the Australian working population: evidence from a cross-sectional survey," Community mental health journal, vol. 52, no. 5, pp. 615-621, 2016.

[29] R. K. Vanderhorst and S. McLaren, "Social relationships as predictors of depression and suicidal ideation in older adults," Aging \& Mental Health, vol. 9, no. 6, pp. 517-525, 2005.

[30] G. Flett, A. Khan, and C. Su, "Mattering and Psychological Well-being in College and University Students: Review and Recommendations for Campus-Based Initiatives," International Journal of Mental Health and Addiction, vol. 17, no. 3, pp. 1-14, 2019. 
[31] G. L. Flett, C. Su, L. Ma and L. Guo, "Academic buoyancy and mattering as resilience factors in Chinese adolescents: An analysis of shame, social anxiety, and psychological distress," International Journal of Child and Adolescent Resilience, vol. 2, no. 1, p. 37, 2014.

[32] S. Nash, M. Longmore, W. Manning and P. Giordano, "Strained Dating Relationships, A Sense of Mattering and Emerging Adults' Depressive Symptoms.," Journal of depression \& anxiety, vol. 013, no. 1, p. Suppl 1, 2015.

[33] O. M. Al-Shawashereh, "Suicidal Ideation in Relation to Self-Esteem among University Students," IUG Journal of Educational and Psychological Studies, vol. 7, no. 2061, pp. 1-31, 2015.

[34] N. Mitsui, S. Asakura, Y. Shimizu, Y. Fujii, A. Toyomaki and Y. K. I. Kako, "The association between suicide risk and self-esteem in Japanese university students with major depressive episodes of major depressive disorder," Neuropsychiatric Disease and Treatment, vol. 10, no .1, pp. 811-816, 2014.

[35] V. R. Wilburn and D. E. Smith, "Stress, self-esteem, and suicidal ideation in late adolescents," Adolescence, vol. 40, no. 157, pp. 33-45, 2005.

[36] E. Choi and I. Choi, "The associations between body dissatisfaction, body figure, self-esteem, and depressed mood in adolescents in the United States and Korea: A moderated mediation analysis," Journal of adolescence, vol. 53, pp. 249-259, Dec 2016.

[37] K. Prihadi, Y. L. Hui, M. J. Chua and C. K. Chang, "Cyber-victimization and perceived depression: Serial mediation of self-esteem and learned-helplessness," International Journal of Evaluation and Research in Education, vol. 8, no. 4, pp. 563-574, 2019.

[38] J. F. Sowislo and U. Orth, "Does low self-esteem predict depression and anxiety? A meta-analysis of longitudinal studies," Psychological Bulletin, vol. 139, no. 1, pp. 213-240, 2013.

[39] G. Elliott, S. Kao and A.-M. Grant, "Mattering: Empirical Validation of a Social-Psychological Concept," Self and Identity, vol. 3, no. 4, p. 339-354, 2004.

[40] M. Dueñas and A. M. Gloria, "¿Pertenezco a esta Universidad?: The Mediating Role of Belonging for Collective Self-Esteem and Mattering for Latin@ Undergraduates," Journal of College Student Development, vol. 58, no. 6, pp. 891-906, 2017.

[41] G. L. Flett, A. L. Goldstein, I. G. Pechenkov, T. Nepon and C. Wekerle, "Antecedents, correlates, and consequences of feeling like you don't matter: Associations with maltreatment, loneliness, social anxiety, and the five-factor model," Personality and Individual Differences, vol. 92, pp. 52-56, Apr 2016.

[42] C. Matera, N. Bosco and P. Meringolo, "Perceived mattering to family and friends, self-esteem, and well-being," Psychology, Health \& Medicine, pp. 1-9, 2019.

[43] G. K. S. Elliott and A. M. Grant, "Mattering: Empirical validation of a social-psychological concept," Self and Identity, vol. 3, no. 4, pp. 339-354, 2004.

[44] T. F. Heatherton and J. Polivy, "Development and validation of a scale for measuring state self-esteem," Journal of Personality and Social psychology, vol. 60, no. 6, pp. 895-910, 1991.

[45] A. T. Beck, C. H. Ward, Mendelson, M. Mock and J. Erbaugh, "An inventory for measuring depression," Archives of General Psychiatry, vol. 4, no. 56, p. 569, 1961.

[46] B. A. J. Van Spijker, P. J. Batterham, A. L. Calear, L. Farrer, H. Christensen, J. Reynolds and A. J. F. M. Kerkhof, "The Suicidal Ideation Attributes Scale (SIDAS): Community-Based Validation Study of a New Scale for the Measurement of Suicidal Ideation," Suicide and Life-Threatening Behavior, vol. 44, no. 4, pp. 408-419, 2014.

[47] A. F. Hayes, Introduction to mediation, moderation, and conditional process analysis: A regression-based approach, Guilford Publications, 2017.

[48] G. C. Elliott, M. F. Colangelo and R. J. Gelles, "Mattering and Suicide Ideation: Establishing and Elaborating a Relationship," Social Psychology Quarterly, vol. 68, no. 3, p. 223-238, 2005.

[49] J. Wagner, O. Lüdtke and U. Trautwein, "Self-esteem is mostly stable across young adulthood: Evidence from latent STARTS models," Journal of Personality, vol. 84, no. 4, pp. 523-535, 2016.

[50] K. Geukes, et al., "Puffed-up but shaky selves: State self-esteem level and variability in narcissists," Journal of Personality and Social Psychology, vol. 112, no. 5, pp. 769-786, 2017. 